\title{
Model for Ensuring Economic Security of a Business
}

\author{
E.L. Arkhipov*, E.Y. Penkova, \\ T.A. Shcherbakova, S.Y. Kazantseva
}

\begin{abstract}
Don State Technical University, Russia, Rostov-on-don
*Corresponding author. Email: ael55555@mail.ru
\end{abstract}

\begin{abstract}
The article is devoted to the study of factors affecting the economic security of business in the current realities. In modern conditions, the operational, tactical and strategic activity of the subject of legal relations occurs in a difficult economic situation, which depends on the external and internal conditions of life of the subject of legal relations, thus, uncertainty and risks i.e. an integral part of a market economy is the most important factor influencing the adoption of relevant decisions in order to ensure the economic security of business. For the purposes of efficiently ensuring the economic security of the business, the authors developed and proposed a special model for ensuring the economic security of the business, which allows, through effective interaction of external and internal factors influencing the institutional unit, mitigate the threats and risks inherent in the subject of legal relations and at the same time ensure its stable development by maximizing the utility function, which fully reflects the economy essence of business security.

Keywords: ensuring economic security, threats and risks, business and legal relations, external and internal
\end{abstract}

factors, resources, results

\section{INTRODUCTION}

In modern conditions, the operational, tactical and strategic activity of the subject of legal relations occurs in a difficult economic situation, which depends on the external and internal conditions of life of the subject of legal relations, thus, uncertainty and risks i.e. an integral part of the market economy is the most important factor influencing the adoption of relevant decisions for business management, which in turn consists of leveling threats and risks while ensuring its stable development. So, in market realities, the most important aspect of the activity of any subject of legal relations is its security and dynamic development, due to the leveling of challenges, threats and risks and maximizing its utility function i.e. attractiveness, namely the increment of ownership. Thus, in order to ensure economic security as a whole, it is necessary and appropriate to use the relevant business management, both through the activities of the control and supervision bodies, and through the adequate work of the legal entities themselves (firms, companies, institutions, organizations, enterprises, etc.) . This is possible by achieving simultaneous protection against both external and internal threats and risks, as well as ensuring the maximization of the stable development of property.

In order to ensure the stable development of the business of any subject of legal relations, it is advisable to proceed from their vector of development of Russia, which in turn is defined in the national security strategy of the Russian Federation, which in turn determines the congruence of the goals of the system as a whole and a specific element of this system i.e. useful interaction of business and government [1].

Thus, it is the provision of economic security for a business that determines its sustainability and ability to adapt to external and internal changes, to prevent, manage and use them in an appropriate manner in order to ensure efficient use of resources and possible sustainable growth of property.

\subsection{Related Work}

The multifaceted nature of the problems of ensuring the economic security of business is caused, firstly, by the desire of institutional units to maximize their profits, and secondly, by the state's intention to create conditions under which the realization of these desires will maximize the benefits for society. So, the strategic directions of the innovative development of socio-economic systems determine the diversity of this interaction, thereby emphasizing its complexity and significance, as well as its feasibility [2]. The interaction of all subjects of the legal relationship is also due to the specifics of their environment, namely the institutional characteristics of the economic security of the region, which in turn affects the competitive features of business in a particular region, as well as its development [3]. The importance and importance of ensuring the economic security of a business is also determined by the technologies used, namely the response speed and databases. Thus, adaptive engineering tools for managing economic security, 
according to G.E. Krokhicheva, V.V. Lesnyak, E.M. Selezneva, E.S. Arakelyants allow you to accelerate the response time for making operational, tactical and strategic management decisions necessary to ensure the economic security of the business [4]. The issues of ensuring economic security are also laid down in normative legal acts, for example, the Strategy for Economic Security of the Russian Federation for the period up to 2030 defines threats and indicators of economic security of both the country as a whole and business in particular, which helps to increase the relevance of this problem [5]. The influence of the information space on the economic security of both business and the region is also an important aspect of ensuring economic security, since the information war often provides an effective tool for competition [6]. The Decree of the President On National Goals and Strategic Tasks of the Development of the Russian Federation for the period up to 2024 defines a development vector for the near future, which must and should be taken into account when carrying out any income-generating activities [7]. S.V. Novoselov and S.A. Panikhidnikovs proceed from the necessity and expediency of a systematic assessment of economic security, since a single element does not always reflect the picture, and the totality of interconnected elements allows us to have a different meaning (synergistic effect) [8]. Thus, a systematic approach to ensuring economic security should be based on a development vector and resource potential. So, the authors of T.L. Sergeeva and L.E. Skripkin pointed out the necessity and expediency of applying methodological approaches to the study of resource potential, which makes it possible to understand what resources and how to use in order to maximize their effectiveness [9]. Methodological approaches to assessing the resource potential directly disclosed by the authors E.A. Bessonova and O.Yu. Mereshchenko, allow us to draw conclusions about the direct impact of changes in resources (both when they are used directly and when they decrease (theft, damage)) on economic security [10]. E.A. Dynnikov, A.N. Milyukin, applying methodological approaches to assessing the resource potential of the region, clearly demonstrated the interrelation of theoretical and practical aspects of economic security in the context of changes in resources, as well as their impact on the institutional unit [11]. It is also worth noting that the resources are theoretically of equal importance both material and non-material, and in practice, the bias towards specific resources is due to their influence on the subject of legal relations, as well as possible profitability. The evaluation of the use of the potential of intangible resources, emphasizing their importance and significance, is devoted to the work of E.V. Mikhalkina and N.A. Kosolapova [12]. Thus, it is necessary and appropriate to use analytical approaches and methods for assessing economic security, and their diversity and application criteria are disclosed by the authors: V.A. Tsvetkov, M.N. Dudin, N.V. Lyasnikov [13]. It is worth noting that a business usually has a link to a specific region, the potential of which is also necessary and appropriate to reveal in order to identify its strengths and weaknesses, as well as additional opportunities and threats [14]. Competitive advantage is also often due to the resource potential of the innovative development of the region's economy, which in turn affects the business development vector [15]. Based on the foregoing, it is logical to trace the relationship between the economic security of the institutional unit and the space in which it is located, as well as the resources and opportunities that they can give to business. The fact of the need for effective management of resources and capital remains inexorable, which is advisable to do by ensuring economic security.

\subsection{Our Contribution}

This article presents a model for ensuring the economic security of a business that allows you to take into account the following factors: the conditions of the external and internal environment of any subject of legal relations, elements of controlling and analysis, relevant accounting, control and supervision aimed at achieving a result. The model of ensuring economic security of a business can be used to manage the subject of legal relations in particular, as well as to ensure the economic security of the business as a whole through a relevant impact on the internal environment and partially external, due to the rational use of the resources of the subject of legal relations with special emphasis on the result. The model was based on the following key points: First, all possible objects for ensuring the economic security of the business were systematized into the following enlarged groups: 1) operational, tactical and strategic initiatives that determine the financial and economic activities of the subject of legal relations; 2) economic, financial and commodity situations, evaluated in the context of fractals of time and space i.e. correlation of temporary flows (investment, innovative, credit and others) with space (strategic platforms, etc.); 3) innovations and their implementation, with an emphasis on the formation, distribution and use of resources, responsibility, timing, life cycle and outcome; 4) property, with an emphasis on the methods of its formation (own, borrowed), profitability, terms, alternatives and increment of the result; 5) costs, expenses, expenses, cost, revenue, income, with an emphasis on their validity and appropriateness; 6) methods and ways of leveling risks, threats and dangers (risk rejection, hedging, use of reserve system aggregates, insurance and selfinsurance (Gant and Harrison method, ie transferring monetary liability to financially burdened violators), 


\section{BACKGROUND}

Secondly, the interaction of external influence (the external environment is imperative and the external environment on which the subject of legal relations can influence), the internal environment, threats, dangers and risks are aimed at identifying and using the economic security zone, while an important element is the understanding of the synergistic effect and congruences goals of institutional units and the external environment (region, country), which in turn provides effective management of the economic security of the region as a whole. Thirdly, the basis of the relationship between the external and internal environment is an idea orienting the subject of the legal relationship to the interrelation of the effect both for the institutional unit and for society, from its legitimate work, with an emphasis on legal interaction and the priority of the effect. Fourth, model iterations provide an understanding of the influence of all factors (both external and internal) on the subject of legal relations with an emphasis on the possibility and expediency of leveling threats and risks while ensuring increased stability (efficiency) of the subject of legal relations, as well as reasonable variability of resources and the result.

\subsection{Paper Structure}

The rest of the article is a model directly developed and proposed by the authors to ensure the economic security of the business, with an emphasis on its description and conclusions.

\subsection{Economic Security}

As a consequence of the foregoing, it is advisable to propose a model developed by the authors to ensure the economic security of the business (Figure 1).

The model of ensuring the economic security of a business is used to manage the subject of legal relations in particular, as well as to ensure the economic security of the business as a whole through a relevant impact on the internal environment and partly external, due to the rational use of the resources of the subject of legal relations with special emphasis on the result.

The model for ensuring economic security of a business has four interconnected enlarged blocks, which are advisable to disclose through the implementation of specific managerial iterations.

The first iteration - management analysis, consists of three interconnected enlarged elements, so the first sub-block (objects) represents resources through which and in the interests of which the management process is carried out. Thus, the relationship between the external (two levels, i.e., imperative and partially imperative) and the internal environment is determined by the capabilities of the institutional unit on the one hand and possible resources (external) on the other, and this is not only about resources that are advisable to attract (loans, loans), etc.), but also about the resources for which it is logical to fight i.e. capital (profit, intangible assets, human capital, and others). It is logical to present this relationship through Figure 2.

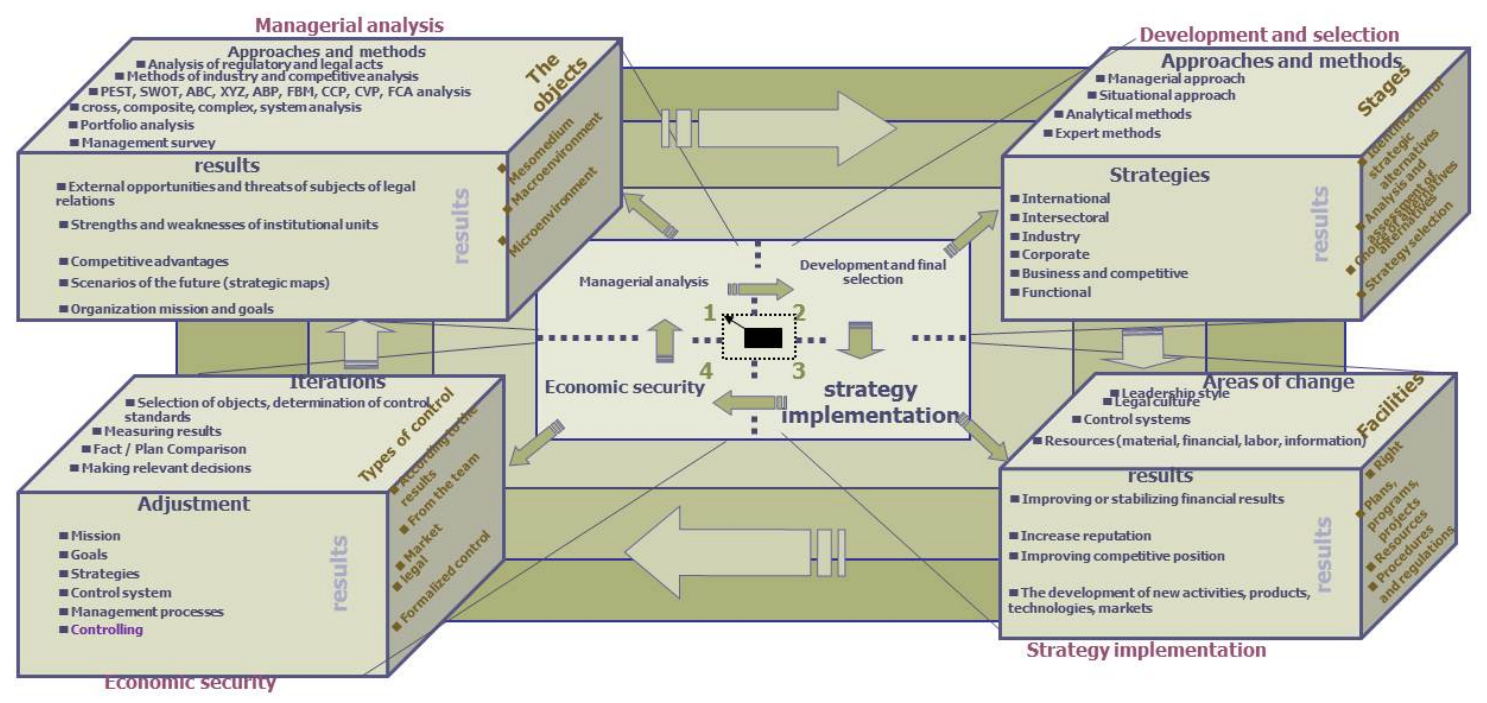

Figure 1 Model for ensuring economic security of a business 


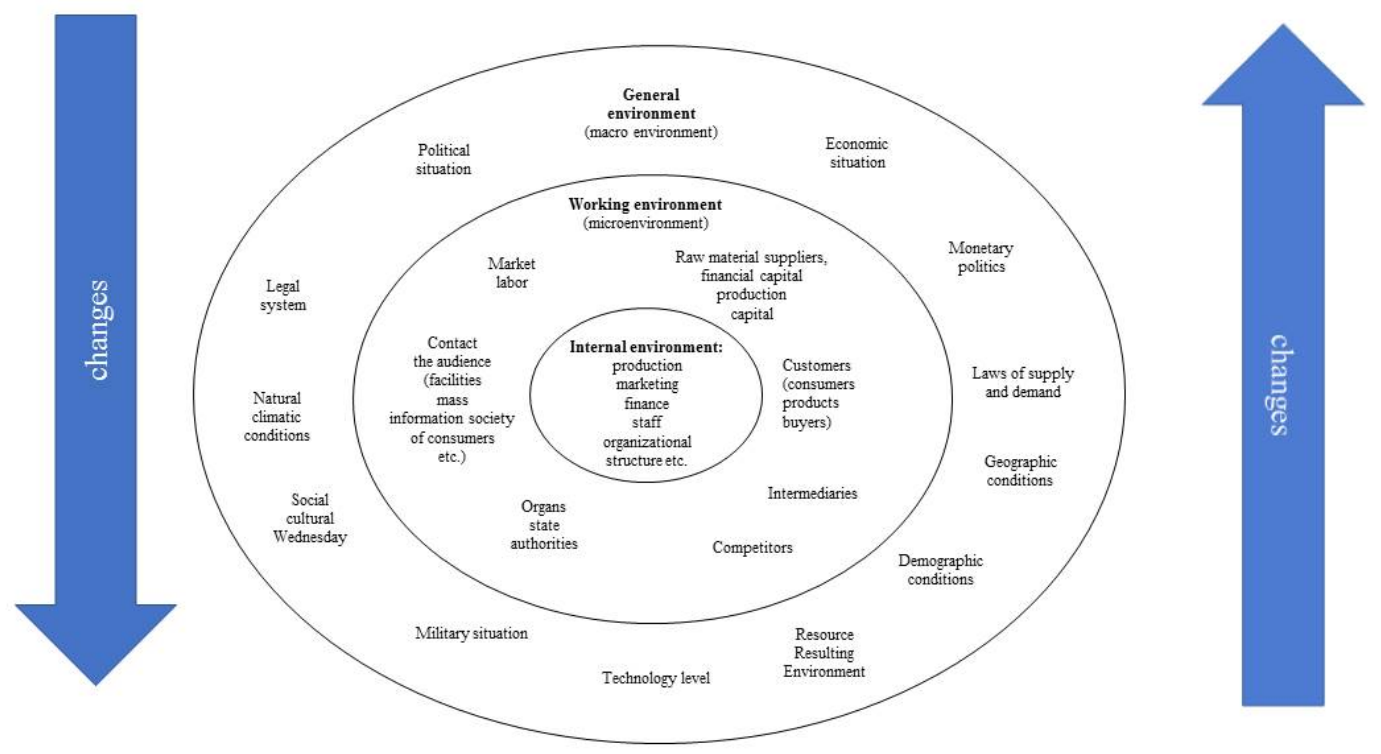

Figure 2 The model of the relationship of external and internal environment

It is worth noting that the system of regional indicators of economic security is important, which in turn is closely linked to a specific institutional unit [16]. The change in resources during this iteration (the second sub-block of the model) is due to management approaches and methods that contribute to making relevant decisions in order to maximize the business utility function. The resulting factor (the third sub-block of the first iteration) is the understanding and justification of operational, tactical and strategic perspectives on the increment of resources, with an emphasis on the prism of the relevant direction (vector) of development. Analysis and monitoring of indicators of economic security of the region allows you to have input data for this iteration [17]. It is worth noting that it is logical and appropriate to consider human capital as resources, since the role of human capital in economic security is difficult to overestimate [18]. Describing the relationship between the external and internal environment, we should proceed from the analysis of approaches to assessing regional processes of socioeconomic security formation [19]. It is also worth paying attention to the variety of organizational and legal forms of institutional units and features of their analysis [20]. Thus, the basis of the model of the relationship between the external and internal environment is the understanding and use of three interrelated levels in the life of legal entities, which are the main blocks of the model, which in turn consist of sub-blocks. The first enlarged block is a macroenvironment, i.e. a General environment that has a more imperative impact, but it is important to understand that the interaction can also be reversed, and it increases in proportion to the capabilities and institutional unit. Thus, the chain of external factors is represented by twelve subblocks. The first sub-block of the model represents the economic situation, it reveals the full diversity of the influence of the economic situation on the subject of legal relations, i.e. defines the economic realities that affect the institutional unit, as well as those in which it is necessary to work, i.e. to maximize its utility function. Thus, it is often economic situations that determine the vector of business development in market conditions, since any commercial structure strives to maximize its capital, and it is the economy that determines the success of this. The second block of the model defines monetary policy, i.e. the financial conditions under which you have to work, it is worth noting their importance, which is difficult to underestimate. So, for example if you take the refinancing rate and track its impact on the economy, it may be noted that because of it's Central Bank manipulates both inflation and demand, as well as amounts of cash, because if there is a trend of increasing rates, this leads to the fact that institutional units I want to take this opportunity to increase its currency, the easiest way in this are contributions (deposits), i.e. by alienating funds from circulation and transferring them to deposits, legal entities reduce demand, which leads to lower prices (since producers and their intermediaries still want to sell products and goods that are no longer in such demand, but have costs for storage, production, etc.), and therefore provides a decrease in inflation, but the reverse side is a slowdown in production, with a possible stop (a decrease in goods and an increase in funds ultimately leads to 
overstated demand and hyperinflation) and a future collapse.It is worth noting that the system of regional indicators of economic security, which in turn is closely related to a specific institutional unit, is important [16]. The change in resources during this iteration (the second sub-block of the model) is due to management approaches and methods that facilitate the adoption of relevant decisions in order to maximize the business utility function. The resulting factor (the third sub-block of the first iteration) is the understanding and justification of the operational, tactical and strategic prospects for increasing resources, with an emphasis on the prism of the relevant direction (vector) of development. Analysis and monitoring of indicators of economic security in the region allows us to have input data at this iteration [17]. It should be noted that it is logical and advisable to take into account human capital as resources, so the role of human capital in economic security can hardly be overestimated [18]. Describing the relationship of external and internal environment, it is worth starting from an analysis of approaches to assessing regional processes of the formation of socio-economic security [19]. It is also worth paying attention to the variety of organizational and legal forms of institutional units and the features of their analysis [20]. Thus, the basis of the model of the relationship between the external and internal environment is the understanding and use in the process of life of the subjects of legal relations of three interconnected levels, which are the main blocks of the model, which in turn consist of subunits. The first enlarged block is a macro environment i.e. the general environment, which has a largely imperative effect, but it is important to understand that the interaction can be the opposite, and it increases in proportion to the capabilities and institutional unit. So, the chain of external factors is represented by twelve subunits. The first sub-block of the model is an economic situation, it reveals the multifaceted impact of the economic situation on the subject of legal relations i.e. determines the economic realities that act on the institutional unit, as well as those under which it is necessary to work i.e. Maximize your utility function. So, it is economic situations that often determine the vector of business development in market conditions. any commercial structure strives to maximize its capital, namely the economy determines the success of this. The second block of the model determines monetary policy i.e. financial conditions under which you have to work, it is worth noting their importance, which is difficult to underestimate. So, for example, if we take the refinancing rate and track its impact on the economy, it can be noted that it is thanks to it that the Central Bank manipulates both inflation and demand, as well as cash volumes, because if there is a trend of increasing rates, this leads to the fact that institutional units want to take this opportunity and increase their currency, the easiest way to do this is to make deposits (deposits), i.e. Alienating funds from circulation and transferring them to deposits, legal entities reduce demand, which leads to lower prices (since manufacturers and their intermediaries still want to sell products and goods that are no longer in such demand, but have storage, production costs, etc.), which means it ensures a decrease in inflation, but the reverse side is the slowdown in production, with its possible halt (a decrease in goods and an increase in cash ultimately leads to excessive demand and hyperinflation s) and the future collapse. Based on this, it is necessary to use monetary policy very skillfully and balance it, achieving alternately both a change in demand and a change in inflation (taking into account the reverse process described above), as well as developing production, banking and other sectors of the economy. The relevance of the collection, reflection and processing of information on the financial and economic activities of business entities of various organizational and legal forms and industry affiliations often determines the completeness, timeliness, information content, and sufficiency of information space for counterparties and segments, which in turn forms the databases necessary for distribution and use of information in order to make relevant operational, tactical and strategic administrative decisions. The third sub-block is the laws of supply and demand, that is, the model is based on the main economic tasks, namely the consumer's task i.e. profitable acquisition (maximum quality at the lowest price), the task of the manufacturer (maximizing profit and profitability on each value chain of the created / created product) i.e. maximizing revenue, the task of economic equilibrium (optimization of price-quality ratios) i.e. a situation in which both the producer and the consumer are fully satisfied, and as the apogee, the task of optimal choice (ideal result) i.e. direct balance of supply and demand, taking into account alternatives, expectations, maximizing the utility function. The fourth sub-block defines the geographical conditions affecting the institutional unit, i.e. those factors that underlie logistics, employee satisfaction, certain aspects and specifics of the production of goods, work, services, as well as remoteness and, accordingly, the cost (both surplus and initial) of all processes. So, for the purpose of relevant management of the subject of legal relations in conditions of risk and uncertainty i.e. For market relations, the crisis manager should, on the basis of statistical data, examine socio-economic processes in order to predict possible threats to economic security, with particular emphasis on leveling them. The fifth sub-block of the model demonstrates demographic conditions i.e. those factors that affect the staff, the number of customers, labor productivity, possible social programs, etc. The sixth subblock of the model is characterized by a resourceresulting environment. So, the management decisions themselves, starting from the stage of origin and ending with the stage of their implementation, are based on a change in resources and results. The seventh sub-block of the model is represented by the level of technology, and it is worth noting that technology and innovation determine not only demand, but also are determined by demand. The eighth sub-block of the macroenvironment is represented by the military situation i.e. by those factors that determine the priorities of a particular state, namely, actions from a position of strength, orientation of spheres of activity, industries, financial flows, interests, etc. The military situation also determines the threshold of tolerance and the 
criteria for citizens to expect from the current situation, not only military, but also economic, political, and others. The ninth subblock of the model characterizes the sociocultural environment, which defines values, criteria of behavior, interests, and other features of human capital. The tenth sub-block determines the natural and climatic conditions, which together with geographical conditions are the most important instrument of motivation (nonfinancial), as well as possible sources of natural wealth, which often determine both the preferred type of activity (from a financial point of view) and the sources of resources. The eleventh sub-block of the model is determined by the legal system, which ultimately determines all legal relations, offenses and crimes, as well as the criteria for imaginary and insignificance in the interaction between the subjects of legal relations. The twelfth sub-block of the model is a political situation affecting the subjects of legal relations, so it is worth noting that the economy determines the desire and desire to get profit, and politics allows the realization of this desire to make legitimate, law, in turn, is a tool that ensures the legitimacy of all of the above. The second block of the model is represented by the working environment i.e. microenvironment in which a specific company (an institutional unit) operates, it consists of seven subunits, each of which is also interconnected. When making effective economic decisions, it is necessary and appropriate to conduct an analysis of possible economic risks and assess them, make and justify forecasts of the dynamics of the development of the main threats to economic security with an emphasis on mechanisms, methods and ways to level them. So, the first sub-block of this block represents suppliers of raw materials, financial capital, production capital i.e. responsible for the formation of the resources of the institutional unit, because it is precisely the ability to provide a competitive advantage at the expense of price that often determine the success in the competition. The second sub-block is represented by customers (consumers of products, buyers), it is worth noting that the customer base is one of the most important resources of the company, moreover, ideally it is called the counterparty base i.e. it lists all customers, competitors, suppliers, other participants in the working environment according to special criteria with an emphasis on the time and resource interval (to whom, when, what), which ultimately ensures the effectiveness of the activity. The third sub-block of the model shows intermediaries, namely the entire chain with a special emphasis on their significance, expediency, strengths and weaknesses, opportunities and threats. In order to manage the subject of legal relations, it is necessary and appropriate to have the ability to collect, analyze, systematize, evaluate and interpret the data necessary to solve professional problems in order to mitigate threats and risks and ensure the stable development of the institutional unit. The fourth sub-block of the model allows monitoring of competitors i.e. to investigate those whose direct and / or indirect activities are designed to harm and / or disadvantage / lessen an institutional unit. In order to obtain relevant information about counterparties (customers, competitors, suppliers, logisticians, contractors, etc.), it is necessary and appropriate to analyze the indicators of financial and economic activity both directly of them and of state bodies and institutions of various forms of ownership i.e. control and supervisory authorities, as well as through public information transmitted without fail (statistical, tax, and other) as a business segment or legal entities. It is worth noting that any activity is related to the industry / sphere, and the appearance / presence of a competitor, by definition, means improving conditions, and therefore encourages the institutional unit to take actions that were not previously planned, despite the fact that they often determine progress and development as a business as a whole, and companies in particular, but the basis of all this, to the point of banality, is simple, namely maximizing profitability / profitability. The fifth sub-block of the model is government bodies that are called upon to exercise control and supervision over the institutional unit. The sixth sub-block of the model reveals the diversity and versatility of the contact audience (mass media, consumer society, etc.), it also gives a legitimate opportunity for interaction and manipulation through the use of mass media. So, an important example of the effective use of the media is the mention of a specific message, for example, if there is a desire to "annoy" a competitor, it is advisable to inform the public about it in a negative perspective, and the information itself and even its truth are not as important as the message itself information coming from different sources and having one message is remembered at the subconscious level as truthful, and not the information itself in all its diversity, but only the message itself i.e. negative or positive, which in turn underlies the conclusions and is a fashion trend, which is subsequently followed. Based on the foregoing, it is worth noting that the apogee of managerial activity is not only the result and effectiveness of work, but also the ability to prepare reports, references and reports on the results of actions taken since it is they who clearly demonstrate the effectiveness and outcome for shareholders, the founder, other interested parties, it is important to note that the relevancy of the interaction of all parts of the value chain, openness, transparency and reliability of the data, as well as their addressability, personalization and timeliness. The seventh sub-block of the model is directly the labor market itself, namely its capabilities and prospects. An important and significant element of ensuring business security is the ability to use mathematical tools to solve economic problems with special emphasis on the laws of supply and demand, the law of equilibrium and development of the subject of legal relations, in order to determine the above factors and criteria. The third block of the model represents the internal environment of the institutional unit through its structure, weaknesses and strengths, as well as the opportunities and threats inherent in it. Based on the foregoing, it is advisable to note that the developed and proposed model of the relationship between the external and internal environment allows us to take into account all the multifaceted factors of the external and internal environment with a special emphasis on their changes and instant response in order to maximize the utility function 
expressed in leveling threats and risks while ensuring stable development of the subject of legal relations. The second iteration - the development and final choice is determined by the decision-making stages for increasing resources, the feasibility and the justified use, with emphasis on the cost, quality and time of special approaches and methods to achieve the goal, and the resulting element of this iteration is the synergistic effect of the generated, involved and used strategies . So, the authors: Krokhicheva G.E., Arkhipov E.L., Bazdikyan M.Yu., Istomin A.V. substantiates the importance and significance of identifying risk situations in the economic security system, which in turn can affect the decision [21]. The third iteration is the implementation of the strategy. This iteration is caused by a change in resources (means of achieving goals), directly by the area of changes during implementation (operational, tactical and strategic, with a focus on their inverse relationship and the possibility of adjustment) of the strategy and the effect of its achievement (capital gain). It is worth noting that the authors: Arkhipov E.L., Krokhicheva G.E., Bazdikyan M.Yu., Vinogradova M.A., Nikogosyan Z.V., Aleksanyan L.G. a special database was created "risk as a factor affecting the assessment of the effectiveness of an investment project in the economic security system", which allows working effectively with risk when implementing a strategy designed to ensure the leveling of threats and risks on the one hand and the stable development of the subject of legal relations on the other hand [22]. The fourth iteration is economic security. This iteration is due to the need and appropriateness of control at each stage of the implementation of the relevant solution with special emphasis on the possibility of adjustment. It is worth noting that since in accounting everything is ultimately expressed in cash, it is advisable to proceed from an increase in the level of economic security in the financial sphere of the subject of legal relations and consider all processes through the financial sphere [23]. An important role is played by the idea of technological entrepreneurship, which allows expanding the category of multifaceted monitoring [24]. So, when implementing this iteration, the types of control are selected, their validity and expediency depends on the hypothetical effect of their use, i.e. criteria of materiality and congruency (the significance of one event for another i.e. a causal relationship of interests and actions), then the control itself takes place, and based on its results, relevant operational, tactical and strategic decisions are made due to the understanding of the alternatives, the effectiveness of the activity as a subprocess, and the process with a focus on the institutional unit and the interests of the owners, as well as the possibility of adjusting the first and subsequent iterations. In ensuring the economic security of the subject of legal relations, it is advisable to proceed from an understanding of global risks, their possible impact and the hypothetical effect of the synergy of global and local risks, with special emphasis on their leveling. The proposed model of ensuring the economic security of a business clearly demonstrates that the subject of legal relations in the course of his activity uses resources and ideas to maximize his capital, while he is faced with problems that can be solved using the relevant process of managing the economic security of the business, which in turn assumes the use of resources of the institutional unit itself and its change through a combination of external and internal factors and working with them, with focus on their future usefulness.

\section{CONCLUSION}

The developed and proposed model for ensuring the economic security of a business allows, through effective interaction of external and internal factors influencing the institutional unit, to mitigate the threats and risks inherent in the subject of legal relations and at the same time ensure its stable development by maximizing the utility function, which fully reflects the economic essence of business security.

\section{ACKNOWLEDGMENT}

The main elements of this work were supported by the Federal Service for Intellectual Property, Patents and Trademarks, so the authors when studying and testing the theoretical and practical aspects of economic security received more than a hundred certificates of state registration of the database in the Federal Service for Intellectual Property, Patents and Trademarks.

\section{REFERENCES}

[1] G.E. Krokhicheva, E. L. Arkhipov, A. S. Voskanova. The national security strategy of the Russian Federation in the system of economic security, Bulletin of Eurasian science. 2017. No1 (38)

[2] O.V. Godina, Y.Y. Kosenkova, L.S. Maksimenko, Y.R. Mezentseva, T.A. Shcherbakova (2019) Strategic Directions of Innovational Development of SocioEconomic Systems. In: Popkova E., Ostrovskaya V. (eds) Perspectives on the Use of New Information and Communication Technology (ICT) in the Modern Economy. ISC 2017. Advances in Intelligent Systems and Computing, vol 726. Springer, Cham DOI: https://doi.org/10.1007/978-3-319-90835-9 14

[3] V.V. Kayukov, A.P. Shikhverdiev. Institutional characteristics of the economic security of a region, Regional Economy, 2018, T. 14, no. 4, 1181-1193. DOI: https://doi.org/10.17059/2018-4-10

[4] G.E. Krokhicheva, V.V. Lesnyak, E.M. Selezneva, E.S. Arakelyants, Adaptive engineering management tools of enterprise economic security, in: Management 
Science Letters, vol. 8, issue 6, 2018, pp. 605-618. DOI: https://doi.org/10.5267/j.msl.2018.4.030.

[5] On the Economic Security Strategy of the Russian Federation for the period up to 2030: Decree of the President of the Russian Federation of 05.13.2017 N 208. URL:

http://www.consultant.ru/document/cons_doc_LAW_2 16629/1d8dcf5824d 5241136fa09b9e9c672ac5d325365 / (access date 10.02. 2020)

[6] A.G. Svetlakov, I.M. Swallow The influence of the information space on the economic security of the region, Economy of the region, 2018, T. 14, no. 2. - S. 474-484 DOI: https://doi.org/10.17059/2018-2-11

[7] On the national goals and strategic objectives of the development of the Russian Federation for the period up to 2024: Decree of the President of the Russian Federation of 05.05.2018 No. 204 URL: http://www.consultant.ru/document/cons_doc_LAW_2 97432/ (accessed 02.10.2020 g.)

[8] C.V. Novoselov, S.A. Panikhidnikov. Systematic assessment of the economic security of the region, Coal. 2018. No. 12 (1113) URL: https://cyberleninka.ru/article/n/sistemnaya-otsenkaekonomicheskoy-bezopasnosti-regiona (accessed: 02/11/2020) DOI: http://dx.doi.org/ 10.18796 / 00415790-2018-12-48-53

[9] T.L. Sergeeva L.E. Skripkina. Methodological approaches to the study of the resource potential of the region, Bulletin of Novgorod State University. 2015. No 87, part 2. S. 97-100

[10] E.A. Bessonova, O.Yu. Mereshchenko. Methodological approaches to assessing the resource potential of the region, Questions of the regional economy, 2016, Vol. 29, No. 4, 17-24.

[11] E.A. Dynnikov, A.N. Milyukin. Methodological approaches to assessing the resource potential of the region, Actual problems of the economy in the context of the reform of modern society. Materials of the IV International Scientific and Practical Conference dedicated to the 140th anniversary of the founding of Belgorod State University. 2016, 95-98

[12] E.V. Mikhalkina, N.A. Kosolapova. Assessment of the use of the potential of intangible resources of the region, Space of Economics. 2018. No1 URL: https://cyberleninka.ru/article/n/otsenka-ispolzovaniyapotentsiala-nematerialnyh-resursov-regiona (accessed:

\section{8-16-1-118-133}

[13] V.A. Tsvetkov, M.N. Dudin, N.V. Lyasnikov. Analytical approaches and methods for assessing the economic security of a region, Regional Economy, 2019, T. 15, no. 1, 1-12 DOI:

https://doi.org/10.17059/2019-1-1

[14] O.A. Lomovtseva. The total resource potential of the region: a methodology for determining and measuring, Scientific reports of Belgorod State University. Series: Economics. Computer science. 2012. No. 1-1 (120) URL:

https://cyberleninka.ru/article/n/sovokupnyy-resursnyypotentsial-regiona-metodologiya-opredeleniya-iizmereniya (accessed: 02/10/2020)

[15] Yu.V. Markina. Resource potential of innovative development of the regional economy, KE. 2011. No5. URL: https://cyberleninka.ru/article/n/resursnyypotentsial-innovatsionnogo-razvitiya-ekonomikiregiona (accessed: 02/12/2020)

[16] A.A. Roshchupkina, T.V. Sidorina. The system of regional indicators of economic security, Bulletin of Eurasian science. 2019. No3 URL:

https://cyberleninka.ru/article/n/sistema-regionalnyhpokazateley-ekonomicheskoy-bezopasnosti (accessed: 03/01/2020)

[17] I.V. Novikova, N.I. Krasnikov. Indicators of the region's economic security, Economics, 2009, No. 11, 132-138

[18] Yu.R. Mezentseva A.M. Bokova, M.N. Pogorelov. The role of human capital in the economic security of the Russian Federation: materials of the scientificpractical conference "Actual issues of ensuring economic security in the Russian Federation in the digital economy." Melbourne, 2018

[19] V.P. Chichkanov, L.A. Belyaevskaya-Plotnik. Analysis of approaches to assessing regional processes of the formation of socio-economic security, Regional Economy, 2016, No3

[20] Mezentseva Yu.R. The model of analysis of foreign economic activity of holding structures, Internet journal "SCIENCE" Volume 8, No 1 (2016) http://naukovedenie.ru/PDF/59EVN116.pdf (free access). Zag from the screen. Yaz. Russian, English

[21] Krokhicheva G.E., Arkhipov E.L., Bazdikyan M.Yu., Istomin A.V. Identification of risk situations in the system of economic security, Internet journal 
[23] Arkhipov E.L. A model for improving economic security in the financial sector. Scientific Review Online Journal No. 122013

http://www.sced.ru/en/index.php?option=com_content \&view=article\&id=236:nauchnoe-obozrenie-122013\&catid=39\&limitstart=9 (free access). Zag from the screen. Yaz. Russian

[24] Khayrullina M.V. Technological entrepreneurship: constraints and development conditions, Russian Entrepreneurship. Creative Economy Publishing House (Moscow) Volume 17, No. 16 (2016) Intellectual Property, Patents and Trademarks. Computer programs for the topology database of integrated circuits. Moscow: FGU FIPS, 2017 